\title{
Affective perception of place: attachment to Kuala Lumpur historical urban places
}

\begin{abstract}
Asian cities have witnessed the changes in the urban landscape and social behaviour in the past decades. As a result of a continuous transformation of urban centres of metropolitan cities, the sense of place is often subdued by a global culture and imagery that may have impacted the people's perception and experience of the city. This paper dwells into the urbanites' relationship with historical urban places in the context of Kuala Lumpur city, Malaysia. Based on a qualitative inquiry, this paper presents the way in which the places shape the perception, knowledge, emotion and memory of the urbanites. The study discovered that Kuala Lumpur urbanites' experience, roles, length of associations and age provided varying reactions that defined the attachment. Place attachment was reflected in the urbanites' economic and cultural dependency on the places they engaged in. The architectural and cultural significance of the places were manifested in the colonial and multi-cultural identity. Thus, reinterpretation of culture and tradition should take into consideration the continuity of place legacy, heritage, place dependency and socio-cultural values. Despite the urbanites' strong identification and knowledge of the built heritage, preserving the place identity is a challenging task due to the complexity of the physical and social environment.
\end{abstract}

Keyword: $\quad$ Place attachment; Dependence; Emotion; Memory; Urbanism 